\title{
GENDER DEMOGRAPHIC DISPARITIES IN BACAU COUNTY
}

\author{
Oana Ancuta Stangaciu \\ Vasile Alecsandri University of Bacau \\ anca_stangaciu@yahoo.com \\ Eugenia Harja \\ Vasile Alecsandri University of Bacau \\ eugenia.harja@ub.ro
}

\begin{abstract}
Gender demographic disparities existing in Bacau County were determined by means of some demographic indicators such as: population, natural growth, live births, marriages, divorces, indicators which have been broken down by gender. The assessment of the disparities between men and women from the point of view of the demographic phenomena emphasize the fact that on the level of Bacau County there is a surplus of female population, as during the whole period subjected to the analysis, the positive and respectively the negative natural growth for the male population were lower and higher respectively than the one registered in the case of the female population. The birth rate, marriage rate and divorce rate phenomena also changed significantly after 1990 ; thus, the average age of marriage increased, and the gender difference also had a certain growth, which caused a shift in the fertility intensity from the age group 20-24 to the very next one - the 25-29 age group.
\end{abstract}

\section{Keywords}

gender disparities; population; birth rate; marriage rate; divorce rate

\section{JEL Classification}

C19; J16

\section{Introduction}

The evolution of population in time, the changes that occur within the age structures and the demographic transition have a series of particular features for the female population and for the male population, thus being confirmed the existence of certain gender disparities in the evolution of the demographic phenomena.

\section{Methodology}

The assessment of the demographic phenomena (evolution of the population, of the birth rate, the death rate, the marriage rate, the divorce rate) from the point of view of gender disparities on the level of Bacau County required the use of certain data bases for the period of time 1990-2013, taken over from TEMPO (https://statistici.insse.ro/shop/), on the site of the National Institute of Statistics. We should mention the fact that the value of the population registered on the $1^{\text {st }}$ July for the period of time 2003-2013 is provisional, as it was calculated through the component method, using administrative data sources for the external migration. These sources do not cover the whole migration phenomenon, especially concerning the emigration. Consequently, there is a serious undervaluation of this phenomenon which leads to an overvaluation of the population residing in Bacau County; therefore, the data presented is provisional, as the number of the population is going to be recalculated. 


\section{Evolution of the population from the point of view of gender disparities} On $1^{\text {st }}$ July 2013, the resident population of Bacau County (provisional data) was of 707,045 inhabitants, 349,109 men (49.4\%) and 357,936 women (50.6\%). The negative values of the natural growth, together with the values of the migration rate, caused the population of the county to diminish year after year starting in 2002, with higher intensity in the case of men. The natural decrease of the population started in 2002, when the negative natural growth in the case of men was higher than the positive natural growth in the case of women and, starting with 2010, when there is also a decrease in the natural growth of the female population, the negative natural growth can be seen in the case of both male and female population.

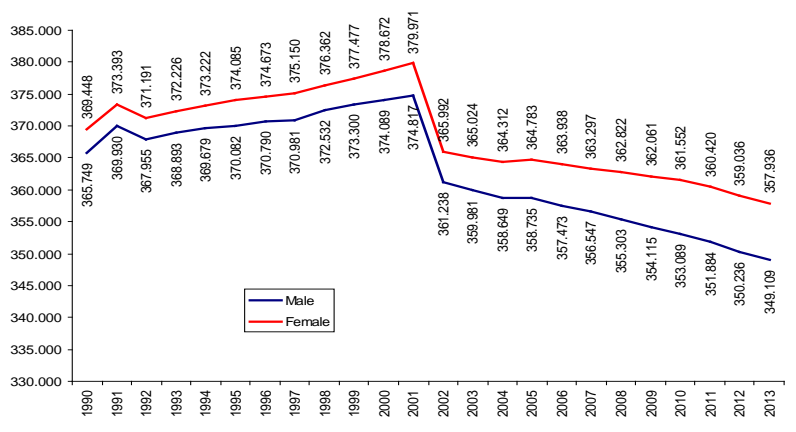

Figure 1. Evolution of the resident population by gender in Bacau County for the period of time 1990-2013 (\%)

Source: processing of the data collected from NIS

For the whole period of time, the positive and the negative natural growth respectively in the case of the male population was lower and respectively higher than the one for the female population, due especially to the male over mortality.

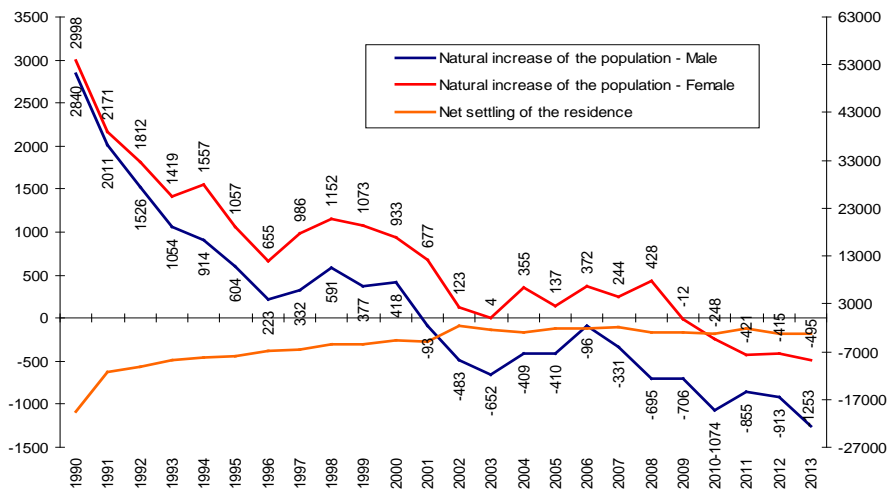

\section{Figure 2. Natural increase by gender and the rate of the migration with residence in Bacau County, for the period of time 2000-2011 \\ Source: processing of the data collected from NIS}

Thus, while in 1990 the positive natural increase of the male population was only 5.3\% lower than that of the female population, after 1996 the gap becomes larger, so that in 2013 the natural decrease of the male population was 2.5 times higher than the 
one registered in the case of the female population. The rate of the migration with residence was negative during the whole period subjected to the analysis.
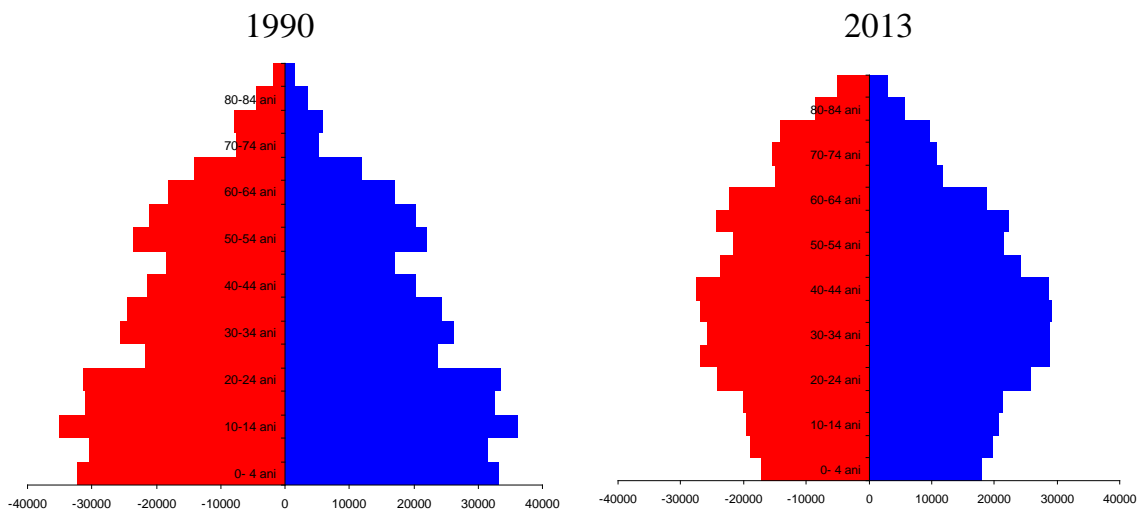

Figure 3. Age pyramid in Bacau County for 1990 and 2013 Source: processing of the data collected from NIS

The age pyramid mirrors in the most accurate way the chronicle of the generations, emphasizing the disparities in the structure of the population, by age and gender. The decrease of the young population narrowed even more the base of the pyramid. Compared to $1^{\text {st }}$ July 1990, in 2013 we can notice a decrease in the percentage of the young population ( 0 -14 years old) from $27.0 \%$ to $16.1 \%$, and an increase in the elder population (65 and over 65 ) from $8.6 \%$ to $14.1 \%$. On the other hand, the percentage of the adult population (15-64 years old) slightly increases in 2013 compared to 1990 from $64.4 \%$ to $69.8 \%$. The population of Bacau County continues to be characterized by an excess of female population both on the whole and on the categories of age over 45 , and even more obviously for the category of age over 80 , when the rate was of 1,538 women for 1,000 men.

\section{Birth rate from the point of view of gender disparities}

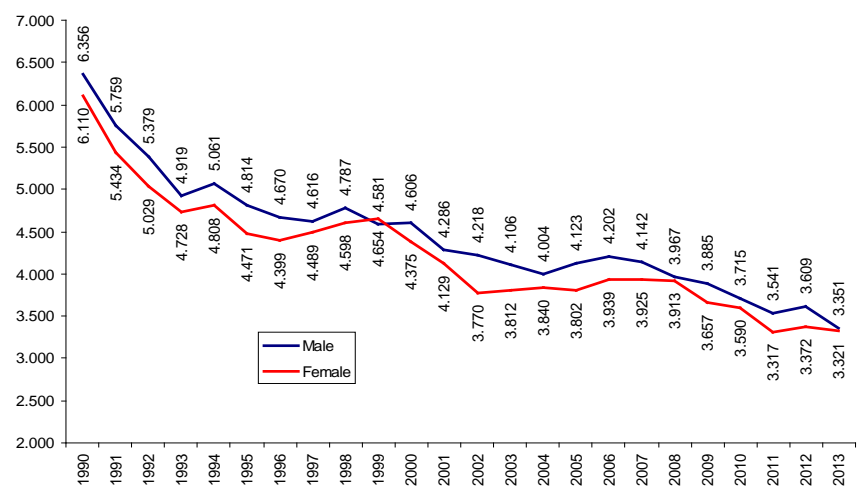

Figure 4. Evolution of the live births on gender in Bacau County for the period of time 1990-2013

Source: processing of the data collected from NIS 
The couples' freedom of deciding on the number of children they want, the requirements of continuous professional training, the social instability and the unemployment are among the main causes which led to the decrease in the number of the live births year after year. During the last years, we can notice that the rhythm in which the birth rate decreases is lower; thus, the number of live births in 2013 was much lower than the one registered in 1990, but compared to the previous year there were only 309 less children born.

In 2013, the birth rate was of 9.4 live births per 1000 inhabitants compared to $16.5 \%$ in 1990, and more than half of the number of children born alive were boys, the report being of 107.0 boys per 100 girls registered in 2012 and of 100.9 in 2013.

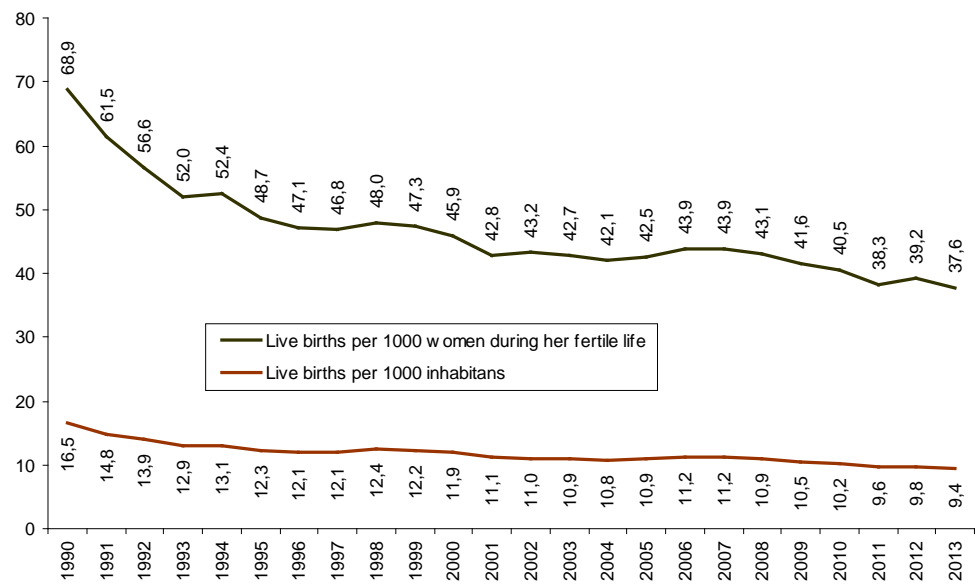

\section{Figure 5. Evolution of the birth rate and the fertility rate in Bacau County for the period of time 1990-2013 \\ Source: processing of the data collected from NIS}

The evolution of fertility was influenced, on one hand, by the demographic behaviour of the couples (which led to smaller families) and, on the other hand, by certain modifications in the number and the structure of the fertile population segment. The level of fertility diminished significantly compared to 1990. Thus, compared to 1990, it kept being low (37.6 children per 1,000 women in 2013, compared to 68.9 children in 1990).

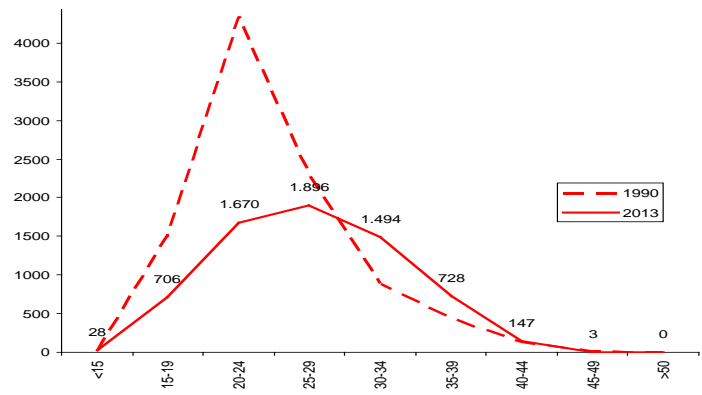

Figure 5. Number of live births by age groups of the mothers in Bacau County in 1990-2013

Source: processing of the data collected from NIS 
Most newborns have mothers between 25-29 years old, this age group continuing to have an important contribution to the evolution of fertility $(28.4 \%$ of the total live births in 2013), while the fertility for the age group 20-24 had the most significant decrease (from $45.1 \%$ of the total live births in 1990 to $25.0 \%$ in 2013). Due to the more and more frequent phenomenon of postponing the pregnancy, we noticed a gradual shift in the fertility intensity for the age group 20-24 to the next one - the 2529 age group.

\section{Marriage rate from the point of view of gender disparity}

As direct consequence of the major modifications that occurred in the Romanian society, the marriage rate phenomenon suffered great changes. Before 1989, there were two characteristics that defined the marriage rate in Romania: the average age at first marriage which was quite low and the high percentage of the people who got married at least once during their life. The modification of the living conditions in the context of the new market economy, the higher requirements concerning the level of qualification and education for getting a stable job, the lack of certain advantages that should stimulate starting new families and the disappearance of restrictions imposed on the type of cohabitation, all these influenced the young people to postpone marriage more frequently. However, in the Romanian society, the prevalent type of union between men and women is still the legal marriage.

In 2013, the number of marriages in Bacau County decreased compared to 1990 by 49.9\%, the marriage rate reaching in 2013 the value of 4.6 marriages per 1000 inhabitants, compared to 8.7 as it was registered in 1990.

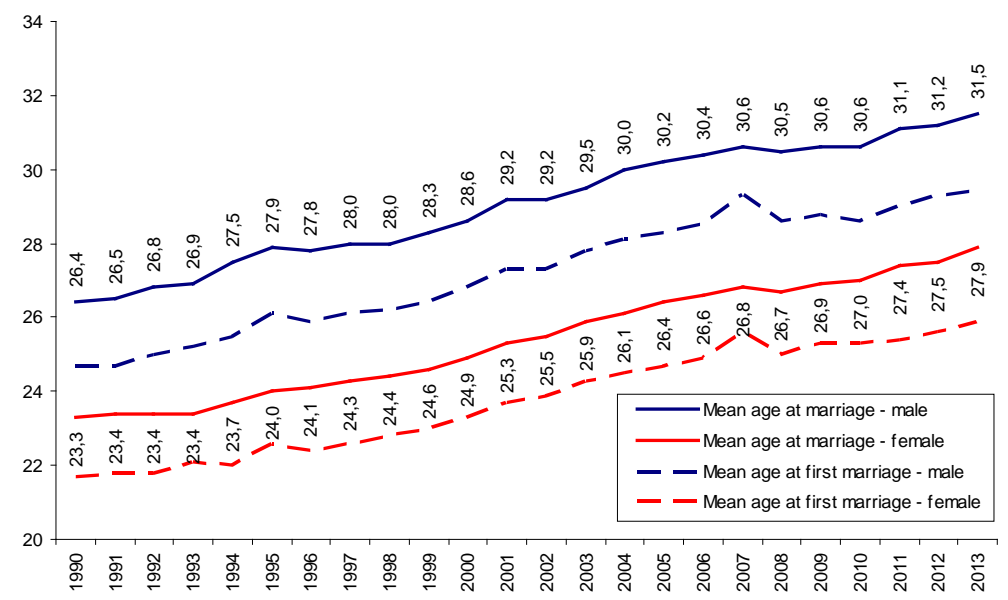

\section{Figure 6. Evolution of the age at marriage by gender in Bacau County in the period of time 1990-2013}

Source: processing of the data collected from NIS

In 2013, the average age at first marriage increased compared to 1990 by 5.1 years in the case of men and 4.6 years in case of women. This fact made the gender difference even greater, its value reaching 3.6 years in 2013. The increase in the average age at first marriage was caused by the decrease in the marriage rate by age, especially in the case of the early ages, up to 25 . 


\section{The divorce rate from the point of view of gender disparities}

The Romanian society continues to be a society in which the family based on legal marriage is still promoted and its stability is encouraged. The average length of marriage which ends in divorce increased in 2013 by 3.7 years compared to 1990 . After the phenomenon had a boost in intensity in the 90', the number of divorces reported to the number of marriages remained relatively constant during the last years, with even a descending trend.

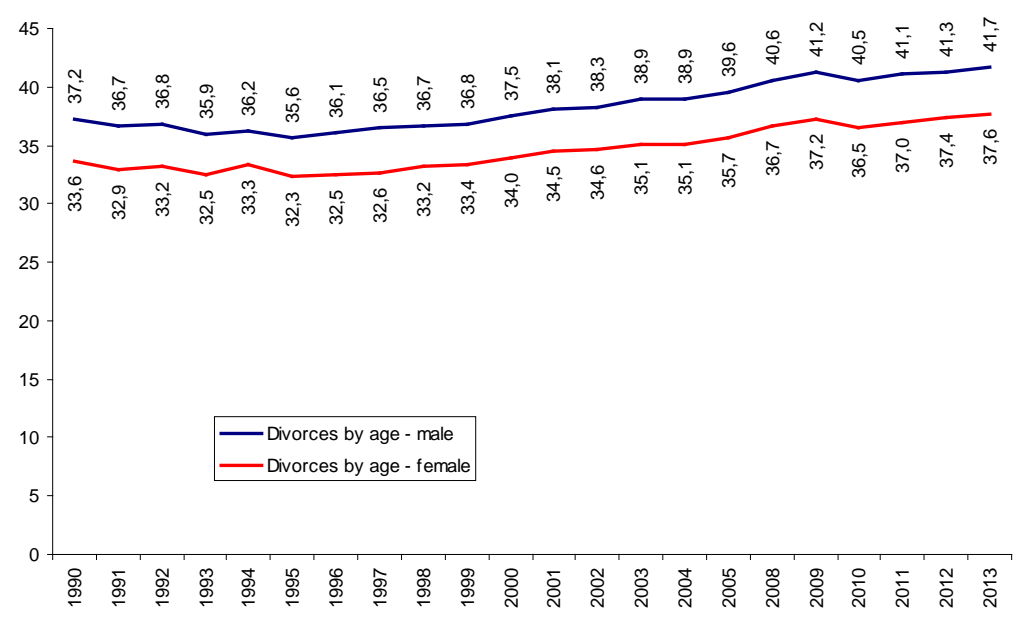

Figure 6. Evolution of the average age at divorce by gender in Bacau County in the period of time 1990-2013

Source: processing of the data collected from NIS

The changes that occurred in the marital behaviour of the population are also reflected in the evolution of divorce. The fact that marriages at an early age and the young families with children were gradually replaced by late, postponed marriages also caused a transition of the average age at divorce. The average age at which men decide to end a marriage through divorce is on average about 4 years higher than in the case of women. The average age at which married people decided to divorce increased by approximately 4 years compared to 1990, in the case of both men and women.

\section{Conclusion}

After the assessment of the gender disparities from the point of view of the evolution of demographic phenomena in Bacau County, we could notice that the population in our county continues to be characterized by an excess female population due to the negative natural growth of the male population which was greater than the one registered in the case of the female population. This excess in female population also caused an increase in the percentage of women from 1,010 women per 1,000 men in 1990 to 1,025 women per 1,000 men in 2013, although more than half of the number of the live births were boys, the report of live births being of 107 boys per 100 girls in 2012 and 101 boys per 100 girls in 2013. There were also changes in the marital behaviour; thus, the average age at first marriage increased by 5.1 years for men and 4.6 years for women compared to 1990, fact which caused the gender differences to become more accentuated, reaching in 2013 the value of 3.6 years. These 
modifications also reflected in the evolution of divorces. The average age when men and women decide to end a marriage through divorce increased by approximately 4 years compared to 1990, and the difference between the average age for men and the average age for women who decide to end a marriage through divorce is also about 4 years.

\section{References}

Caldwell, J. (1982), Theory of Fertility Decline, Academic Press, New York.

Kabeer, N. (1996), Gender, Demographic Transition and the Economics of Family Size: Population Policy for a Human-Centred Development, Geneva, United Nations Research Institute for Social Development.

Filmer, D. (1999), The Structure of Social Disparities in Education: Gender and Wealth, Review Policy research report on gender and development - Working Paper Series, No. 5, pp. 1-66.

Harja, E. (2014), Analysis of the marriages and divorces seasonality in Romania compared to Bacau county during 2010-2013, Studies and Scientific Researches. Economics Edition, No 19, pp. 38-44.

Stângaciu, O. A. (2013), Equality of opportunity between men and women on the labour market - the gender pay gap within the EU member states, Studies and Scientific Researches. Economics Edition, No 18, pp. 95-100. 